Original Article

\title{
Dribbling Training Methods 15 yard Turn and 20 yard Squared For Improving Results Undikma Football
}

\author{
Susi Yundarwati ${ }^{1}$, Intan Primayanti, ${ }^{2}$ \\ ${ }^{12}$ Pendidikan Jasmani Kesehatan dan Rekreasi, Universitas Pendidikan Mandalika, Indonesia \\ Susiyundarwati@ikipmataram.ac.id ${ }^{1}$, Intanprimayanti@ikipmataram.ac.id ${ }^{2}$
}

\begin{abstract}
ABSTRAK
Tujuan untuk mengetahui pengaruh metode latihan dribbling 15 yard turn dan 20 yard squared peningkatan hasil dribbling sepakbola UNDIKMA, kurang dalam hal kelincahan, kecepatan, dan kesimbangan, pada saat menggiring bola. Metode Rancangan yang digunakan dalam penelitian ini adalah rancangan atau desain dengan model eksperimen. Jenis penelitian menggunakan Eksperimen "Two Group Pretest-posttest Design. Teknik pengambilan sampel menggunakan purposife sampling diman berjumlah 22 pemain UNDKMA yang dibagi menjadi 2 kelompok Dari hasil analisis data pengaruh Metode latihan dribbling 15 yard turn dan 20 yard squared peningkatan hasil dribbling sepakbola UNDIKMA. Nilai thitung antara latihan dribbling 15 yard turn dengan X1 (dribbling) sebesar $t_{\text {hitung }} 7,362$. nilai thitung antara X2 20 yard squared antara (dribbling) sebesar 7.358, dan nilai $\mathrm{t}_{\text {hitung }}$ secara simultan antara $\mathrm{Y}$ dan $\mathrm{X} 1, \mathrm{X} 2$, menarik kesimpulan analisis tabel pada taraf signifikan 5\% dengan jumlah sampel 11-1 = 10 sebesar 1.812. bahwa hipotesis "Ha" (diterima) maka penelitian ini signifikan) Simpulan metode latihan dribbling 15 yard turn dan 20 yard squared peningkatan hasil dribbling sepakbola UNDIKMA dapat menigkatkan dribbling sepakbola, Sesuai dengan S.O.P secara vaiatif, efektif dan efisien, sesuai dengan pola gerak motorik atlit sepakbola.
\end{abstract}

Kata kunci: dribbling 15 yard turn, 20 yard squared, dribbling Sepakbola.

\section{ABSTRACT}

The aim is to see the effect of the 15 yard turn and 20 yard squared dribbling training methods on the improvement of UNDIKMA football dribbling results, lacking in terms of agility, speed and balance, when dribbling. The design method used in this study is a design or design with an experimental model. This type of research uses the Experiment "Two Group Pretest-posttest Design. The sampling technique used purposive sampling where 22 UNDKMA players were divided into 2 groups. From the results of data analysis the effect of the dribbling training method 15 yard turn and 20 yard squared increase the results of UNDIKMA football dribbling. The value of tcount between 15 yard turn dribbling and XI (dribbling) is tcount 7,368. The value of tcount between $X 2$ is 20 yards squared (dribbling) of 7,358, and the value of tcount simultaneously between $Y$ and X1, X2, draws from the table analysis at a significant level of 5\% with a sample size of 11-1 = 10 of 1,812. that the hypothesis "Ha" (accepted), then this research is significant) Conclusion of the 15 yard turn 
88 | Susi Yundarwati ${ }^{1}$, Intan Primayanti ${ }^{2}$

Dribbling Training Methods 15 yard Turn and 20 yard Squared For Improving Results Undikma Football

and 20 yard squared dribbling training methods, the increase in the results of UNDIKMA football dribbling can improve football bling soccer.

keyword: dribbling 15 yard turn, 20 yard squared, dribbling Sepakbola

Received: 02-06-2021; Accepted: 16-06-2021; Published: 20-06-2021

(C) 2021 Universitas Suryakancana e-ISSN: 2721-7175(online) p-ISSN: 2089-2341 (cetak)

\section{PENDAHULUAN}

Sepak bola merupakan salah satu cabang olahraga yang dimainkan di luar ruangan. Olahraga ini dimainkan di atas sebuah kawasan yang lapang oleh dua kelompok yang disebut tim. Setiap pemain harus memiliki kemampuan melakukan operan (passing), menggiring (dribbling), menembak (shooting). Selain cara - cara tersebut, ada cara lain yang bisa dilakukan oleh para pemain yang tidak membawa bola, seperti bergerak 4 (empat), mencari ruang kosong, membantu dan melindungi pemain yang sedang membawa bola (Parnell \& Richardson, 2014)

Teknik dasar yang harus di kuasai setiap pemain adalah dribbling.(Kadek Aditya Darma Putra, I Ketut Yoda, 2016) Dribbling dipengaruhi oleh beberapa faktor seperti pengalaman bermain yang dimiliki, semakin lama seseorang berlatih tentunya keterampilan juga akan semakin baik (Taufik, 2018). Perkenaan kaki terhadap bola juga menentukan keberhasilan dribbling karena perkenaan kaki yang benar dengan bola akan memudahkan pesepakbola bergerak dengan cepat. (Halouani et al., 2014) UNDIKMA singkatan dari (Univesitas Pendidikan Mandalika Mataram) adalah salah Satu tim sepak bola di Mataram sebagain besar anggotanya adalah mahasiswa UNDIKMA yang tergabung UKM TIM sepakbola sebagai icone olahraga kota dan seluruh kabupaten kota di NTB yang paling sering mengadakan turnamen sepak bola.

Latar belakang dari penelitian ini adalah diman sebanyak $50 \%$ atlet sepak bola UNDIKMA banyak mengalami kesalahan dalam melakukan dribbling diakibatkan kurang faktor, kelincahan, kecepatan dan kesimbangan dilihat pada hasil latihan dan pertandingan. Dilihat dari ugensi masalah diatas $30 \%$ tidak kurang kelincahan, dan kecepatan, $40 \%$ keterampilan kurang variasi model latihan secara variatif, pada saat menggiring bola.perlu adanya latihan yang lebih baik karena dribbling adalah 
89 | Susi Yundarwati ${ }^{1}$, Intan Primayanti ${ }^{2}$

Dribbling Training Methods 15 yard Turn and 20 yard Squared For Improving Results Undikma Football

kompenen paling penting dalam sepak bola. (Setiawan I, Yuwono C, Puji E, 2017) Dengan permaslahan seperti itu maka perlu dilaksanakan model latihan yang bisa meningkatkan hasil dribbling efektif,

Rasional Hasil pengamatan dilapangan banyak pemain yang memiliki kurang dalam hal kelincahan, kecepatan, dan kesimbangan, karena menurut (Tarju \& Wahidi, 2017) bahwa kompenen biomotor ini sangat penting dalam sepakbola serta kurang variasi model latihan secara efektif, variatif, monoton, terukur, pada saat menggiring bola, dalam mempertahankan bola sangat kurang sehingga pemain tersebut sering terjatuh, maka saat menggiring bola terlihat lambat model latihan agar mampu memperbaiki dengan menggunakan metode latihan dribbling 15 yard turn dan 20 yard squared, maka dari itulah perlu dilakukan sebuah penelitian ini.

Urgensi permaslahan yang didasar keperihatinan akan mandeknya prestasi sepakbola Indonesia pada umumnya di kalangan remaja dan daerah khususnya UNDIKMA (Nusa Tenggara Barat) dan keinginan untuk mengembangkan bakat-bakat para pemain di kalangan Remaja Mataram akan terjadi degradasi. Maka perlu sebuah solusi dalam penelitian ini dilakukan atas dasar kondisi tersebut, dengan metode latihan dribbling 15yard turn dan 20 yard squared, menngkatkan hasil dribbling efektif, efesien, pada saat menggiring bola. Peneliti bahwa Muhammad Irkham. 2015. "Pengaruh Latihan Agility Ladder Exercise Dengan Metode Lateral Run Drill Terhadap Peningkatan Keterampilan Dribbling Pada Pemain SSB Pelangi U17 Tahun 2015, penelitian ini dapat meningkatkan keterampilan dribbling bola memilih metode latihan agility ladder exercise mengingat ini lebih baik untuk pergerakan keterampilan pemain saat membawa bola.

Kebaruan penelitian (novellty), model latihan dribbling 15 yard turn da 20 yard squared untu meningkatkan hasil dribbling sepakbola yang di modifikasi sesuuai dengan S.O.P sebelumnya. Kesimpulan bahwa model yang saat ini buat adalah spesifikasi latihan dribbling metode latihan dribbling 15 yard turn dan 20 yard squared, sehingga untuk meningkatkan latihan dribbling secara vaiatif, efektif dan efisien, sesuai dengan pola gerak motorik atlit tersebut, fakor yang terpenting adalah pada saat gerak motorik. Tujuan akhir penelitian metode latihan dribbling 15 yard turn 
90 | Susi Yundarwati ${ }^{1}$, Intan Primayanti ${ }^{2}$

Dribbling Training Methods 15 yard Turn and 20 yard Squared For Improving Results

Undikma Football

dan 20 yard squared ini untuk menghasilkan desain metode latihan dribbling yang dimanfaatkan dalam proses latihan. Kontribusi dapat meningkatkan metode latihan dribbling 15 yard turn dan 20 yard squared peningkatan hasil dribbling sepakbola UNDIKMA Sesuai dengan S.O.P secara vaiatif, efektif dan efisien, sesuai dengan pola gerak motorik atlit sepakbola.

\section{METODE}

Rancangan yang digunakan dalam penelitian ini adalah rancangan atau desain dengan model eksperimen. Yang dimaksud dengan metode penelitian eksperimen adalah suatu cara yang sistematis dan objektif untuk mencari hubungan sebab akibat antara dua variabel atau lebih yang sengaja ditimbulkan oleh peneliti sebagai treatment dengan kontrol secara ketat (Hulfian, 2014:9). Jenis penelitian menggunakan Eksperimen "Two Group Pretest-posttest Design".

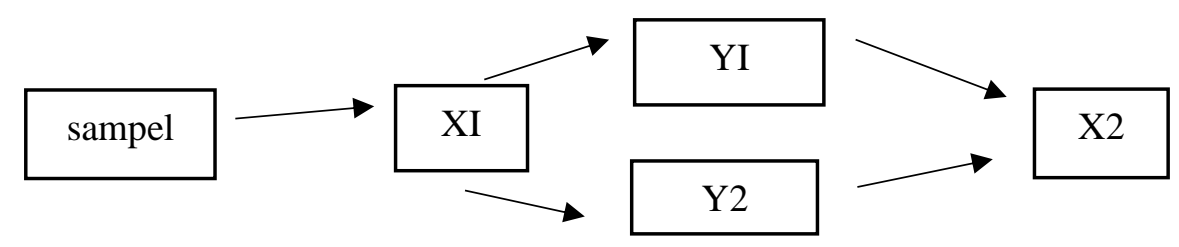

Gambar 1. Rancangan Penelitian (Arikunto, 2010) Keterangan

Sampel adalah bagian dari jumlah dan karekteristik yang dimiliki oleh populasi tersebut (Winnico, MG Gaos, 2019) Jadi dari pendapat tersebut di atas dapat disimpulkan bahwa yang dimaksudkan dengan populasi dalam karakteristik subjek keseluruhan pemain tergabung dalam UKM olahraga yang karakteristik yang populasinya berjumlah 30 pemain yang berumur 20-22 Tahun pemain UNDIKMA FC Mataram yang menjadi sampel adalah berjumlah 22 orang teknik sampling menggunakan purposive sampling. Pengumpulan data dilakukan dengan metode dokumentasi dan tes perbuatan. Metode dokumentasi adalah suatu cara mengumpulkan data-data berupa dokumentasi pemain UNDIKMA tahun 2021. Sedangkan metode tes perbuatan digunakan untuk memperoleh data-data tentang peningkatan dribbling sepak 
91 | Susi Yundarwati ${ }^{1}$, Intan Primayanti ${ }^{2}$

Dribbling Training Methods 15 yard Turn and 20 yard Squared For Improving Results Undikma Football

bola, metode observasi dalam penelitian ini dimaksudkan untuk melihat apakah proses pengumpulan data dilakukan benar atau tidak.

\section{HASIL DAN PEMBAHASAN}

\section{Hasil Penelitian}

Data pada hasil yang sebelumnya dilakukan Pre Test atau tes awal dan Post Test yang dilakukan pada siswa, sebelum penerapan latihan dribbling 15 yard turn dan 20 yard squared peningkatan hasil dribbling sepakbola UNDIKMA.

Tabel 1.1 Hasil Data Pre-test dan Post-test dribbling 15 yard turn

\begin{tabular}{|c|c|c|c|c|c|}
\hline \multirow{2}{*}{ No } & \multirow[b]{2}{*}{ Nama } & \multirow[b]{2}{*}{ XI } & \multirow[b]{2}{*}{ XII } & & \multirow[t]{2}{*}{$D^{2}$} \\
\hline & & & & D & \\
\hline & & & \multicolumn{3}{|c|}{ (XII-XI) } \\
\hline 1 & $\mathrm{X} 1$ & 11,8 & 11,62 & 0,18 & 0,0324 \\
\hline 2 & $\mathrm{X} 2$ & 11,73 & 11,6 & 0,13 & 0,0169 \\
\hline 3 & X3 & 10,4 & 10 & 0,4 & 0,16 \\
\hline 4 & $\mathrm{X} 4$ & 10,4 & 10,02 & 0,38 & 0,1444 \\
\hline 5 & X5 & 10,4 & 10 & 0,4 & 0,16 \\
\hline 6 & X6 & 10,7 & 10,1 & 0,6 & 0,36 \\
\hline 7 & X7 & 11,65 & 11,15 & 0,5 & 0,25 \\
\hline 8 & $\mathrm{X} 8$ & 11,42 & 11,04 & 0,38 & 0,1444 \\
\hline 9 & $\mathrm{X} 9$ & 10,51 & 10,07 & 0,44 & 0,1936 \\
\hline 10 & $\mathrm{X} 10$ & 9,64 & 9,12 & 0,52 & 0,2704 \\
\hline \multirow[t]{2}{*}{11} & $\mathrm{X} 11$ & 9,72 & 9,24 & 0,48 & 0,2304 \\
\hline & & 118,37 & 113,96 & 4,41 & 1,9625 \\
\hline
\end{tabular}

Pada langkah ini data hasil tes dari dribbling sepak bola yang sudah tercantum dalam tabel diatas kemudian dimasukkan kedalam rumus " $t$-test" sebagai berikut :

$$
\begin{gathered}
t=\frac{\sum D}{\sqrt{\frac{N \cdot \sum D^{2}-\left(\sum D\right)^{2}}{(N-1)}}} \\
t=\frac{4.41}{\sqrt{\frac{11.1,9625-19,44}{(11-1)}}}
\end{gathered}
$$


92 | Susi Yundarwati ${ }^{1}$, Intan Primayanti ${ }^{2}$

Dribbling Training Methods 15 yard Turn and 20 yard Squared For Improving Results Undikma Football

$$
\begin{aligned}
& t=\frac{4.41}{\sqrt{\frac{12,93}{10}}} \\
& t=\frac{4.41}{\sqrt{0.359}} \\
& t=\frac{4.41}{0,599} \\
& t=7.362
\end{aligned}
$$

\begin{tabular}{|c|c|c|c|c|c|}
\hline & & & & & $D^{2}$ \\
\hline No & Nama & XI & XII & $\mathrm{D}$ & \\
\hline & & & & $\begin{array}{l}\text { (XII- } \\
\text { XI) }\end{array}$ & \\
\hline 1 & $\mathrm{X} 1$ & 11,99 & 11,72 & 0,27 & 0,0729 \\
\hline 2 & $\mathrm{X} 2$ & 11,9 & 11,68 & 0,22 & 0,0484 \\
\hline 3 & $\mathrm{X} 3$ & 10,6 & 10,11 & 0,49 & 0,2401 \\
\hline 4 & $\mathrm{X} 4$ & 10,64 & 10,2 & 0,44 & 0,1936 \\
\hline 5 & X5 & 10,62 & 10,18 & 0,44 & 0,1936 \\
\hline 6 & X6 & 10,71 & 10,22 & 0,49 & 0,2401 \\
\hline 7 & $\mathrm{X} 7$ & 10,68 & 10,21 & 0,47 & 0,2209 \\
\hline 8 & X8 & 10,66 & 10,1 & 0,56 & 0,3136 \\
\hline 9 & X9 & 10,74 & 10,23 & 0,51 & 0,2601 \\
\hline 10 & X10 & 10,51 & 10,32 & 0,19 & 0,0361 \\
\hline 11 & X11 & 9,51 & 9,16 & 0,35 & 0,1225 \\
\hline & & 118,56 & 114,13 & 4,43 & 1,9419 \\
\hline
\end{tabular}

Tabel 1.2 Hasil Data Pre-test dan Post-test latihan 20 yard squared

Pada langkah ini data hasil tes dari dribbling sepak bola yang sudah tercantum dalam tabel diatas kemudian dimasukkan kedalam rumus " $t$-test" sebagai berikut :

$$
\begin{gathered}
t=\frac{\sum D}{\sqrt{\frac{N \cdot \sum D^{2}-\left(\sum D\right)^{2}}{(N-1)}}} \\
t=\frac{4.43}{\sqrt{\frac{11.1 .9419-19,624}{(11-1)}}}
\end{gathered}
$$


93 | Susi Yundarwati ${ }^{1}$, Intan Primayanti ${ }^{2}$

Dribbling Training Methods 15 yard Turn and 20 yard Squared For Improving Results Undikma Football

$$
\begin{gathered}
t=\frac{4.43}{\sqrt{\frac{13,183}{10}}} \\
t=\frac{4.43}{\sqrt{0,363}} \\
t=\frac{4.43}{0,602} \\
t=7.358
\end{gathered}
$$

Tabel 1.3 Selisih Pre-tes dan Post Tes Metode latihan dribbling 15 yard turn dan 20 yard squared

\begin{tabular}{ccc}
\hline Uraian & Pre-Tes & Post Tes \\
\hline dribbling 15 yard turn & 9,72 & 9,24 \\
dribbling 20 Yard Squared & 9,51 & 9,16 \\
\hline
\end{tabular}

Hasil Selisih Pre Tes Dan Pos Tes 15 Yard Dan 20 Yard Squared

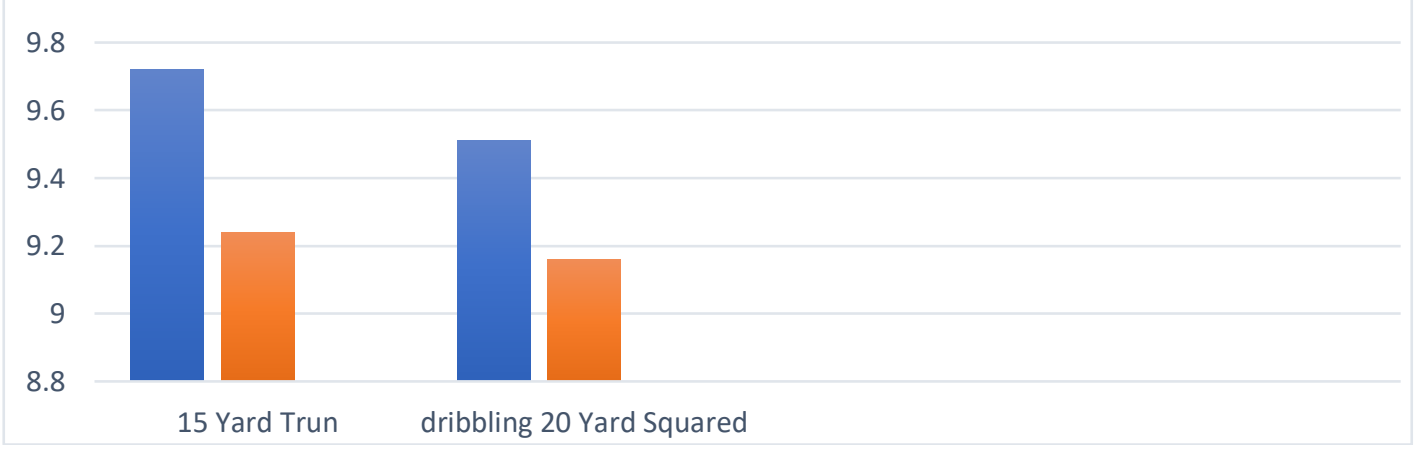

Gambar 1.1 Pre-tes dan Post Tes Metode latihan dribbling 15 yard turn dan 20 yard Menarik kesimpulan squared.

Dari hasil analisis data statistik latihan dribbling 15 yard turn terhadap Metode latihan dribbling 15 yard turn peningkatan hasil dribbling sepakbola UNDIKMA Nilai thitung X (dribbling 15 Yard Turn ) sebesar 7.362 nilai secara simultan antara Y dan X menarik kesimpulan analisis tabel pada taraf signifikan 5\% dengan jumlah sampel ( $n$ - 1 ) yaitu 10 sebesar 1.812. Maka dapat disimpulkan bahwa dilihat dari $t_{\text {hitung }}>t_{\text {tabel }}$ (7.362 > 1.812.). Dari hasil analisis data statistik latihan 20 yard squared terhadap 
94 | Susi Yundarwati ${ }^{1}$, Intan Primayanti ${ }^{2}$

Dribbling Training Methods 15 yard Turn and 20 yard Squared For Improving Results

Undikma Football

metode peningkatan dribbling 20 Yard Squared peningkatan hasil dribbling sepakbola UNDIKMA. Nilai thitung X (dribbling 20 Yard Squared) sebesar 7.358 nilai secara simultan antara $\mathrm{Y}$ dan $\mathrm{X}$ menarik kesimpulan analisis tabel pada taraf signifikan 5\% dengan jumlah sampel ( $\mathrm{n}-1$ ) yaitu 10 sebesar 1.812. Maka dapat disimpulkan bahwa dilihat dari $t_{\text {hitung }}>t_{\text {tabel }}(7.358>1.812)$. (Ha) Diterima Ada pengaruh Metode latihan dribbling 15 yard turn dan 20 yard squared peningkatan hasil dribbling sepakbola UNDIKMA, (Ho) Ditolak tidak ada Ada pengaruh Metode latihan dribbling 15 yard turn dan 20 yard squared peningkatan hasil dribbling sepakbola UNDIKMA.

\section{Pembahasan}

Berdasarkan hasil pengolahan dan analisis data terhadap hasil penelitian dengan menggunakan analisis $t$-test terhadap hipotesis yang di ajukan dalam penelitian ini ternyata teruji kebenarannya. Temuan-temuan dalam penelitian ini seperti yang dikemukakan di atas merupakan hasil analisis secara statistik yang akan peneliti kaji lebih lanjut. Metode latihan dribbling 15 yard turn dan 20 yard squared peningkatan hasil dribbling sepakbola UNDIKMA. Nilai thitung antara latihan dribbling 15 yard turn dengan X1 (dribbling) sebesar thitung 7.362. nilai thitung antara X2, metode 20 yard squared antara (dribbling) sebesar 7.358, dan nilai thitung secara simultan antara $\mathrm{Y}$ dan $\mathrm{X} 1, \mathrm{X} 2$, menarik kesimpulan analisis tabel pada taraf signifikan 5\% dengan jumlah sampel 11-1 = 10 sebesar 1.812. bahwa hipotesis "Ha" (diterima) maka penelitian ini signifikan.

Dribbling 15-yard turn merupakan modifikasi dari suatu bentuk variasi latihan baku yang bisa membantu meningkatkan kecepatan dan keterampilan dribbling bola dengan menempatkan tiga cone membentuk segitiga sama sisi dangan jarak antar cone 5 yard dan mempraktikan dribbling bola melalui ketiga cone tersebut secara berurutan. Bentuk latihan ini sesuai dengan kebutuhan dribblling yang mengharuskan orang untuk bergerak dengan cepat dan mengubah arah dengan tangkas. Latihan dribblling 20 Yard Square yaitu pemain di wajibkan dribblling di daerah yang berbentuk square (kotak) yang setiap sudutnya di beri 4 cone setiap cone berjarak kira-kira sekitar 5 yard. 
95 | Susi Yundarwati ${ }^{1}$, Intan Primayanti ${ }^{2}$

Dribbling Training Methods 15 yard Turn and 20 yard Squared For Improving Results Undikma Football

Penelitian terdahulu,.(Kadek Aditya Darma Putra, I Ketut Yoda, 2016). Pengaruh Pelatihan Slalom Dribbling Terhadap Kelincahan Dan Vo 2 Maks Siswa Peserta Ekstrakurikuler Sepak Bola Hasil penelitian Hasil penelitian: Simpulan: 1) Ada pengaruh latihan dribbling terhadap kelincahan dan Vo2mazx.

Hasil temuan faktor kecepatan dribbling merupakan salah satu faktor terpenting dalam keberhasilan permainan sepakbola. Menurut (Bingham et al., 2014)Keterbatasan seorang pemain membawa atau dribbling ke arah daerah permainan lawan dapat menyebabkan kurangnya variasi permainan dari suatu tim karena tidak berhasil mengembangkan permainan ke daerah lawan. Perlu adanya latihan dribbling yang sangat mendukung dalam sepak bola (Pajerska et al., 2020)Maka Upaya untuk meningkatkan kecepatan dribbling dengan cara latihan dribbling 15 yard turn dan 20 yard squared baik dan efisien, efektif terencana dan terprogram secara baik.

Dampak penelitian kepada pelatih dan pembina Metode latihan dribbling 15 yard turn dan 20 yard squared peningkatan hasil dribbling sepakbola UNDIKMA memberikan latihan yang tersusun dan terprogram. 2) Diharapkan dapat dijadikan bahan perbandingan bagi peneliti dalam melakukan penelitian mengenai dribbling bola pada cabang olahraga sepakbola secara vaiatif, efektif dan efisien, sesuai dengan pola gerak motoric. dan keterbatasannya terlihat bahwa minat dan motivasi dalam latihan sangat kurang indikasi dari itu hasil tes di lapangan juga terhadap etode latihan dribbling 15 yard turn dan 20 yard squared peningkatan hasil dribbling kurang maksimal.

\section{SIMPULAN}

Jadi dari hasil penelitian Dari hasil analisis data pengaruh Metode latihan dribbling 15 yard turn dan 20 yard squared peningkatan hasil dribbling sepakbola UNDIKMA. Nilai thitung antara latihan dribbling 15 yard turn dengan X1 (dribbling) sebesar thitung 7,362. nilai thitung antara X2, 20 yard squared antara (dribbling) sebesar 7.358, dan nilai thitung secara simultan antara $\mathrm{Y}$ dan X1, X2, menarik kesimpulan analisis tabel pada taraf signifikan 5\% dengan jumlah sampel 11-1 = 10 sebesar 1.812. bahwa hipotesis "Ha" (diterima) maka penelitian ini signifikan. Diterima Ada 
96 | Susi Yundarwati ${ }^{1}$, Intan Primayanti ${ }^{2}$

Dribbling Training Methods 15 yard Turn and 20 yard Squared For Improving Results Undikma Football

pengaruh Metode latihan dribbling 15 yard turn dan 20 yard squared peningkatan hasil dribbling sepakbola UNDIKMA.

\section{DAFTAR PUSTAKA}

Bingham, D. D., Parnell, D., Curran, K., Jones, R., \& Richardson, D. (2014). Fit Fans: perspectives of a practitioner and understanding participant health needs within a health promotion programme for older men delivered within an English Premier League Football Club. Soccer and Society, 15(6), 883-901. https://doi.org/10.1080/14660970.2014.920624

Halouani, J., Chtourou, H., Gabbett, T., Chaouachi, A., \& Chamari, K. (2014). Smallsided games in team sports training: A brief review. In Journal of Strength and Conditioning Research. https://doi.org/10.1519/JSC.0000000000000564

Kadek Aditya Darma Putra, I Ketut Yoda, I. N. S. (2016). e-Journal IKOR Universitas Pendidikan Ganesha PENGARUH PELATIHAN SLALOM DRIBBLING TERHADAP KELINCAHAN DAN VO 2 MAKS SISWA PESERTA EKSTRAKURIKULER SEPAK BOLA Kadek Aditya Darma Putra, I Ketut Yoda , I Nyoman Sudarmada e-Journal IKOR Universitas Pendidikan. E-Journal IKOR Universitas Pendidikan Ganesha, 1(1).

Pajerska, K., Zajac, T., Mostowik, A., Mrzyglod, S., \& Golas, A. (2020). Post activation potentiation (PAP) and its application in the development of speed and explosive strength in female soccer players: A review. Journal of Human Sport and Exercise, 16(1), 122-135. https://doi.org/10.14198/jhse.2021.161.11

Parnell, D., \& Richardson, D. (2014). Introduction. Soccer and Society, 15(6), 823827. https://doi.org/10.1080/14660970.2014.920619

Setiawan I, Yuwono C, Puji E, B. D. (2017). Journal of Physical Education, Sport, Health and Recreations. TINGKAT KETERAMPILAN DASAR PERMAINAN SEPAK BOLA PADA SISWA SEKOLAH DASAR Hendri, 6(2), 133-139. http://journal.unnes.ac.id/sju/index.php/peshr

Tarju, T., \& Wahidi, R. (2017). Pengaruh Metode Latihan Terhadap Peningkatan Passing Dalam Permainan Sepak Bola. JUARA: Jurnal Olahraga, 2(2), 66. 
97 | Susi Yundarwati ${ }^{1}$, Intan Primayanti ${ }^{2}$

Dribbling Training Methods 15 yard Turn and 20 yard Squared For Improving Results

Undikma Football

https://doi.org/10.33222/juara.v2i2.35

Taufik, M. S. (2018). Meningkatkan Teknik Dasar Dribbling Sepakbola Melalui Modifikasi Permainan. Jurnal Maenpo : Jurnal Pendidikan Jasmani Kesehatan Dan Rekreasi, 8(1), 26.

Winnico, MG Gaos, M. T. (2019). Peningkatan Keterampilan Shooting Kaki Bagian

Dalammelalui Audio-Visual. Jurnal Maenpo: Jurnal Pendidikan Jasmani Kesehatan Dan Rekreasi, 09(1), 1-7. 